\title{
Methane hydrate nucleation and growth from the bulk phase: Further insights into their mechanisms
}

\author{
Olivia Fandiño, Livio Ruffine*
}

IFREMER, Département REM, Unité des Géosciences Marines, 29280 Plouzané, France

*: Corresponding author : Livio Ruffine, tel.: +33298224888 ; fax: +33298224570 ;

email address : livio.ruffine@ifremer.fr

\begin{abstract}
:
Methane hydrate nucleation and growth from a bulk phase has been investigated using a quiescent high-pressure view cell. Several hydrate formation/dissociation cycles have been performed at two different initial pressures (10 MPa and 19.5 MPa). Every experiment was performed with a maximum of five consecutive cycles of cooling/heating. For each cycle, the induction time of incipient hydrate formation has been determined. On one hand, results obtained from cycles using fresh water led to the conclusion that the hydrate formation process is rather stochastic, with induction times varying over a large scale. On the other hand, the whole dataset enabled us to investigate on the controversial memory effect of water which may have the ability to fasten the hydrate formation.

Moreover, video monitoring has been performed for most of the hydrate formation/dissociation cycles and pictures were taken at different steps of the hydrate formation. The analysis of the results allowed a better understanding of the hydrate nucleation and growth. Two different mechanisms have been observed according to the initial pressure. At initial pressure around $10 \mathrm{MPa}$, a thick layer of hydrates was created within a couple seconds at the water-gas interface. This layer hinders the gas diffusion and considerably slows down their growth. At $19.5 \mathrm{MPa}$, the hydrate formation occurs within a larger volume of the bulk phase, and still close to the water-gas interface. The small hydrate crystals are rather dispersed, allowing the diffusion of gas and enhancing the hydrate growth until the formation of a hard layer at the interface of both phases.
\end{abstract}

Keywords: Methane hydrates ; Nucleation ; Growth ; Quiescent reactor ; Memory effect 


\section{Introduction}

Gas hydrates are crystalline materials made from water and light molecules under low temperature and high-pressure conditions [1-3]. The water molecules form the lattice defining the crystal structure, within which light molecules can be inserted. There is a large variety of species, called guest molecules, which can be enclathrated within the water lattice. Light hydrocarbons like methane, ethane, propane and isobutane, as well as carbon dioxide, are the more commonly studied hydrates. However, other molecules like hydrogen, hydrogen sulphur, nitrogen and helium can also be considered as guest molecules [3-7].

Historically, gas hydrates have been investigated to deal with flow assurance issues during natural gas production and transportation [8-14]. Their formation within the pipeline can cause severe economic loss to oil and gas companies as they often have to shut down the production in order to take out the created hydrate plug. Besides, hydrates are widely encountered in nature [2, 15-17]. They form gas reservoirs, mainly methane, within marine and freshwater sediments at water depths greater than $300 \mathrm{~m}$ and in the permafrost [18-20]; and correspond to at least twice the whole exploitable hydrocarbon reserves identified up to date [21-23]. This makes natural gas hydrates a promising potential energy resource. Therefore, there is a real need for building up scientific insights which will be used to design geo-processes for hydrate exploitation for the next decades [16, 24-26].

Amongst all the aspects which need to be considered to gain a better understanding of the hydrate behaviour, the study of its formation processes, namely its nucleation and growth, is of special importance because they influence their distribution in nature. In addition, the physical and chemical characteristics of the geological matrix can further complicate these processes. Thus, to first learn about the mechanisms which are behind both processes bulk phase experiments are required.

Like other crystallisation processes hydrate formation is not governed by thermodynamic laws but is rather stochastic [27-30]. In fact, significant differences have been observed in terms of period of time elapsed for the detection of hydrates from repeated experiments in the bulk phase. Accordingly, to compare and combine experiments of hydrate formation one should consider discussing about the key parameters defining the nucleation and the growth, namely the induction time, the driving force and the memory effect.

The induction time is defined as being the elapsed time for the hydrate nuclei to achieve a critical size for initiating the hydrate growth [31-37]. The rate at which hydrate nuclei are formed then grow up is related to the thermodynamic driving force [38-42]. The latter can be of different origins and the most common driving forces are subcooling and supersaturation $[38,39,41,43,44]$. Besides the induction time and the driving forces, the history of the water involved in the hydrate formation seems to play a significant role in the kinetics of hydrate formation. However, although for the two former there is a consensus regarding their influence on the hydrate formation kinetics, the importance of the latter is more controversial. Several studies have attested that the water molecules can keep a local spatial organization during a certain time after hydrate dissociation or ice melting [29, 37, 43, 45, 46]. Such molecular arrangement would increase the probability for the hydrate nuclei to achieve the critical size and then will fasten their growth. Other researchers have also provided evidence from experiments of the non-existence of this memory effect [47-49].

Those studies highlight the fact that even if these properties have been studied, fundamental issues regarding hydrate nucleation and growth are still unclear to date. In this work, we present an experimental study on the hydrate nucleation and growth processes in the bulk phase. The aim is to get more insights into the influence of pressure and successive hydrate formation/ dissociation cycles on these processes. 


\section{Experimental apparatus, materials and procedure}

\subsection{Apparatus}

A high-pressure apparatus was used for the experiments (Fig. 1). The heart of the system consists of a variable-volume type high-pressure cell equipped with two sapphire windows. The device has already been described by Ruffine et al. [50]. Briefly, it allows performing both kinetics and phase equilibrium measurements. The temperature inside the cell chamber was measured with a K-type thermocouple with an accuracy of $\pm 0.4 \mathrm{~K}$. Pressure measurements were performed using a S-10 WIKA pressure transmitter with an accuracy of $\pm 0.01 \mathrm{MPa}$. Calibrations of both sensors were carried out at the Laboratoire National de Métrologie et d'Essais (LNE), France. A refrigerated circulator bath Ministat 230 from Huber was used for thermal regulation. For each experiment, temperature and pressure were monitored and recorded using a Eurotherm Chessell 6100 paperless data-logger.

\subsection{Materials}

Milli $Q$ water, with a resistivity of $18.2 \mathrm{M} \Omega \cdot \mathrm{cm}$ at $298.15 \mathrm{~K}$ and a total organic carbon of less than $3 \mathrm{ppb}$, was used after degassing by a heating method. Methane was supplied by Air Liquide with a claimed minimum mole fraction purity of 0.995 and used without further purification.

\subsection{Experimental procedure}

All experiments were done at constant volume to keep the same system geometry, and thus avoiding the influence of changing the size of the liquid surface area [31, 33]. The chosen volume was of $19.0 \pm 0.5 \mathrm{~cm}^{3}$. Methane was injected into the cell directly from a cylinder while in the case of water an Optos high-pressure liquid metering pump from Eldex was used. The exact amount of injected water was determined by weighing the water container before and after the injection using an Excellence E-5500S balance from Sartorius. The claimed accuracy of the latter was of $0.01 \mathrm{~g}$. For all experiments, $10 \mathrm{~g}$ of water was used. Two injection procedures were considered.

1) Water was injected into the pre-evacuated high-pressure cell. Subsequently, the temperature was set to $293.1 \mathrm{~K}$. Methane was injected afterwards to $10 \pm 0.2 \mathrm{MPa}$. This value of pressure was high enough to enable the consumption of an amount of gas exceeding the solubility limit and promote the hydrate formation after decreasing the temperature. The system was left for 24 hours, and then the temperature was lowered to $274.6 \mathrm{~K}$ to enable hydrate nucleation. Hydrates were detected by visual observation through the sapphire window and/or by a pressure drop at constant temperature. Hydrate growth was further monitored during 72 hours from the time of incipient hydrate formation. Finally, the hydrates were dissociated by applying a stepwise heating procedure with an increment of 2.5 K every 5 hours until the final temperature of $293.1 \mathrm{~K}$ was reached.

2) For experiments at $19.5 \pm 0.4 \mathrm{MPa}$, the procedure was the same except that methane was injected first, followed by the injection of water. Several tests have been done previously in order to determine the suitable methane pressure needed to reach an overall system pressure close to $19.5 \mathrm{MPa}$ after adding $10 \mathrm{~g}$ of water. It is important to notice that one experiment was also performed at $10 \mathrm{MPa}$ using this procedure in order to verify the 
influence of the order by which water and methane were injected. It turned out that the injection order has no impact on the nucleation time for this system.

With the aim to better understand the influence of the memory effect of water on the hydrate formation, we also carried out several cycles of hydrate formation/dissociation with the same injected (methane + water) mixture. Fig. 2 illustrates the procedure which has been applied. It corresponds to the temperature profile obtained from experiment $A$. Thus, the initial temperature condition was identical at the beginning of each cycle whereas the waiting time in between successive cycles could be modified for the purpose of the experiments. In the case of experiment $A$, the waiting time in between cycles was of 5 hours and always the same. The cooling step was very fast, therefore stable temperature conditions were achieved in less than 30 minutes. Once methane hydrates were detected the system was left for around 72 hours, followed by another stepwise heating with an increment of $2.5 \mathrm{~K}$ every 5 hours in order to completely dissociate the hydrates. Overall, each hydrate formation/ dissociation cycle lasted at least 112.5 hours. A maximum of five cycles were performed for each experimental run.

\section{Results and discussion}

\subsection{Hydrate nucleation and growth}

As can be seen in Fig. 3, our experiments of hydrate formation and dissociation can be graphically represented by the classical $(p, T)$ profile. Two cycles of hydrate formation/ dissociation at different initial pressures for the (methane + water) system are shown. The hydrate formation and dissociation cycle at $10 \mathrm{MPa}$ exhibits a classical shape in Fig. 3a with a well-defined equilibrium point. This was not the case for all experiments at $19.5 \mathrm{MPa}$. The equilibrium point was sometimes less easier to determine as can be seen in Fig. $3 \mathrm{~b}$. The latter illustrates the $(p, T)$ path for experiment $\mathrm{F}$. It is characterized by a pressure drop during the heating step which is likely due to the breaking of the hydrate layer. Thus, the gas was allowed to diffuse easier into the supersaturated water phase, enhancing the hydrate growth process. Nevertheless, for all experiments presented here, the hydrate nucleation was detected accurately owing to permanent video monitoring.

Fig. 4 and 5 show the temporal evolution of the hydrate layer formed from the experiments $A$ and $\mathrm{F}$ for an initial pressure of $10 \mathrm{MPa}$ and $19.5 \mathrm{MPa}$, respectively. As expected, hydrates are mainly formed at the gas-liquid interface in both cases, and accordingly have nucleated at this region. However, the growth process is different from one experiment to another. Here, for the experiment at $10 \mathrm{MPa}$, the hydrate layer looks thick, therefore hindering the gas diffusion into the bulk phase (Fig. 4b, 4c and 4d). One can see that there is no significant growth during the 66 hours following the incipient hydrate formation where the photo shoots have been taken. The formation of the hydrate layer was fully captured for the $4^{\text {th }}$ hydrate formation/ dissociation cycle of experiment A. The resulting video is attached to this paper (Hydrate-Formation_Ifremer.mp4). The video shows the formation of the layer at the real recording-speed. It is formed within a couple of seconds. One could also observe the creation of waves on the water surface just before the hydrate-layer formation. This might be due to a rapid change in the water density at the interface just before the hydrate formation, the release of heat, or the combination of both. On the other hand, at $19.5 \mathrm{MPa}$, although the hydrates are still formed at the gas-liquid interface the crystals are more dispersed within the bulk phase making the layer weaker (Fig. 5b, 5c and 5d). Thus, the gas can continue to diffuse into the water. The hydrate layer becomes gradually stronger until it grows into a thick one which is capable of hindering the gas diffusion (Fig. $5 e$ and $5 f$ ).

Thus, two different hydrate nucleation and growth processes have been observed from our two series of experiments: a rapid formation of the layer at the lower pressure explored, 
whereas at the higher pressure this layer formation is much more slower enabling the nucleation of hydrate crystals within a larger upper slide of the bulk phase. Such hydrate formation mechanisms have already been reported in the literature [27, 29, 51-53] for different media. However, to our knowledge the formation of dispersed nucleation points within a bulk phase and at quiescent conditions has not been reported yet.

Pictures of the hydrate distribution within the high-pressure view cell have also been taken at the end of each cycle for the experiment B (72 hours after their formation). They are presented in Fig. 6. One can clearly notice different growth patterns. Surprisingly, with increasing cycles, more hydrates nucleate as droplets on the sapphire window in the gas phase even sometimes where the presence of water droplets on the window was not observed prior to the formation. Thus, repeated cycles of hydrate formation and dissociation favour the transfer of water vapour into the methane-rich gas phase. The latter becomes saturated in water and promotes the hydrate nucleation directly from the vapour phase [54, $55]$ by condensation on the sapphire window.

\subsection{Memory effect versus stochastic process}

According to literature survey, the nucleation and growth of hydrates can be fastened when the water has previously experienced hydrate formation. This is the so-called memory effect of water which is often mentioned in work dealing with hydrate formation. However, the memory effect is often opposed to the stochastic behaviour of hydrate formation. To evaluate the importance of both effects on the kinetics of methane hydrate formation, experiments were repeated without changing the chemical load. Tables 1 and 2 summarize the results obtained from all experiments performed in the frame of this study. Fig. 7 and 8 illustrate the $(p, T, t)$ profiles resulting from the first cycle of hydrate formation for the experiments performed at an initial pressure of $10 \mathrm{MPa}$ and $19.5 \mathrm{MPa}$, respectively. The slight decrease of the pressure at the beginning of the experiments is attributed to the dissolution of the methane in water at $293.1 \mathrm{~K}$. Then, an important pressure drop is observed during the cooling to $274.6 \mathrm{~K}$ due to the increase of methane solubility in water at low temperature. It is interesting to notice that the values of the pressure drop are the same for all experiments performed at the same initial pressure. They are of $0.9 \mathrm{MPa}$ and $2.4 \mathrm{MPa}$ for experiments at $10 \mathrm{MPa}$ and $19.5 \mathrm{MPa}$, respectively. The incipient of hydrate formation is indicated by a third pressure drop which is more obvious at low pressure. Fig. 9 represents the whole duration for the experiments $A, B, C$ and $F$ for which five hydrate formation/ dissociation cycles have been performed. The pressure at the end of each heating step slightly decreases from one cycle to the next one.

Overall, our study of hydrate formation/ dissociation cycles reveals that the induction time can vary widely even when the experiments were done at the same ( $p, T$, cell geometry) conditions. Moreover, the difference between experiments $B$ and $C$ lies in the sequence of the injection of methane and water. As for the other experiments at $10 \mathrm{MPa}$, water was injected first for experiment $\mathrm{C}$, while it was injected after the methane for experiment $\mathrm{B}$. Both experiments lead to very similar values of induction time for the first cycle, suggesting that the order of injection of the chemical components has no influence on the formation kinetics in the frame of our study. As expected, the induction time for the first hydrate formation cycle is much longer for the experiments at $\sim 10 \mathrm{MPa}$ with values ranging from 76.5 to 207 hours. These values range from less than 30 minutes to 18.2 hours for experiments at $\sim 19.5 \mathrm{MPa}$. This is in agreement with the statements of previous researchers whom stressed the importance of supersaturation of the hydrate formation kinetics [38, 41, 43, 44]. Here, by reducing the pressure by half the induction time is at least four times longer. For experiment $\mathrm{A}$, the waiting time between each hydrate formation and dissociation cycle was kept to $5 \mathrm{~h}$. One can see from Table 1 that the induction time decreases considerably from the first cycle to the fourth one, then substantially increases again for the fifth cycle. The independence of 
this parameter on the history of each cycle proves that there is no memory effect enhancing the hydrate formation kinetics. This is strengthened by experiments $B, C$ and $F$, where five cycles have been performed. Here, the induction time can also either increase or decrease from one cycle to the next one. Moreover, the experiments $\mathrm{G}, \mathrm{H}, \mathrm{I}$ and $\mathrm{J}$ further support the stochastic nature of hydrate formation. In fact, the experiments $\mathrm{G}$ and $\mathrm{J}$ are characterized by very similar induction times for the first cycle. This holds true for the experiments $\mathrm{H}$ and $\mathrm{I}$. However, while the waiting time before the second cycle of hydrate formation and dissociation for the experiments $G$ and $I$ is of 24 hours, the resulting induction time is of nearly three hours for the former and less than thirty minutes for the latter.

Thus, the analysis of the full dataset reveals that the induction time can either increase or decreases and it is irrespective of both the number of cycles of hydrate formation and dissociation the system has previously experienced, and the duration of the waiting time between cycles. In addition, although the induction time for the second cycle is shorter than this for the first cycle for all experiments, the overall results is in disagreement with the finding of Wu et al. [37]. They showed that memory effect vanish for temperature above 298 $\mathrm{K}$. However, such a comparison would be made with care as our hydrate formation procedures and our apparatus geometry were different.

\section{Conclusion}

Gas hydrates are leading to new energy perspectives and new developments in gas-storage and separation processes. Up to date, none of these applications are economically viable and this step will not be overcome without a good understanding of hydrate nucleation and growth. The study presented in this paper consists of a series of isothermal experiments conducted in order to better understand the nucleation and growth processes of hydrates from the bulk phase. Two initial pressures were explored. The results enabled us to observed two different mechanisms of hydrate formation: The first one was characterized by a rapid formation of a hydrate layer at the gas-liquid interface as reported by previous workers. The second one was defined by the occurrence of multiple nucleation points within the bulk phase. The former mechanism was observed at the lower investigated pressure and quickly limits the hydrate growth process, whereas the latter was encountered at the higher investigated pressure. Regarding the memory effect, this study suggests that there is no systematic decrease of the induction time when the water has already experienced hydrate formation. Thus, the stochastic nature of the nucleation seems to prevail over the memory effect.

\section{Acknowledgments}

This work received financial support from the Institut Carnot Ifremer-EDROME. The authors are grateful to this institute for the grant.

\section{References}

[1] Makogon Y. Hydrates of hydrocarbons. Pennwell Publishing Company, Tulsa, Oklahoma, 482 p. 1997.

[2] Max M. Natural gas hydrate: in oceanic and permafrost environments: Kluwer Academic Pub; 2003.

[3] Sloan ED, Koh CA. Clathrate hydrates of natural gases: CRC Press; 2008. 
[4] Liang S, Kusalik PG. Exploring nucleation of $\mathrm{H}_{2} \mathrm{~S}$ hydrates. Chemical Science. 2011;2:1286-92.

[5] Londono D, Kuhs WF, Finney JL. Enclathration of helium in ice II: the first helium hydrate. Nature. 1988;332:141-2.

[6] Prasolov EM, Tokarev IV, Ginsburg GD, Soloviev VA, Eltsova GM. Helium and other noble gases in gas-hydrate sediments of the Hakon Mosby Mud Volcano. Geo-Marine Letters. 1999;19:84-8.

[7] Zhong DL, Yang C, Liu DP, Wu ZM. Experimental investigation of methane hydrate formation on suspended water droplets. Journal of Crystal Growth. 2011;327:237-44.

[8] Creek JL. State-of-the-art perspectives of natural gas hydrates in industrial flow assurance. Abstracts of Papers of the American Chemical Society. 2009;237.

[9] Gao S. Investigation of Interactions between Gas Hydrates and Several Other Flow Assurance Elements. Energy \& Fuels. 2008;22:3150-3.

[10] Gbaruko BC, Igwe JC, Gbaruko PN, Nwokeoma RC. Gas hydrates and clathrates: Flow assurance, environmental and economic perspectives and the Nigerian liquified natural gas project. Journal of Petroleum Science and Engineering. 2007;56:192-8.

[11] Koh CA, Sum A, Sloan ED. Natural Gas Hydrates in Flow Assurance: Elsevier Science; 2010.

[12] Mokhatab S, Wilkens RJ, Leontaritis KJ. A review of strategies for solving gas-hydrate problems in subsea pipelines. Energy Sources Part a-Recovery Utilization and Environmental Effects. 2007;29:39-45.

[13] Sloan ED. Fundamental principles and applications of natural gas hydrates. Nature. 2003;426:353-9.

[14] Sloan ED. A changing hydrate paradigm-from apprehension to avoidance to risk management. Fluid Phase Equilibria. 2005;228:67-74.

[15] Makogon Y, Holditch S, Makogon T. Natural gas-hydrates-A potential energy source for the 21st Century. Journal of Petroleum Science and Engineering. 2007;56:14-31.

[16] Max M, Johnson A, Dillon W. Economic geology of natural gas hydrate: Kluwer Academic Pub; 2006.

[17] Max M, Lowrie A. Oceanic methane hydrates: A frontier gas resource. Journal of Petroleum Geology. 1996;19:41-56.

[18] Khlystov O, De Batist M, Shoji H, Hachikubo A, Nishio S, Naudts L, et al. Gas hydrate of Lake Baikal: Discovery and varieties. Journal of Asian Earth Sciences. 2013;62:162-6.

[19] Naudts L, Khlystov O, Granin N, Chensky A, Poort J, De Batist M. Stratigraphic and structural control on the distribution of gas hydrates and active gas seeps on the Posolsky Bank, Lake Baikal. Geo-Marine Letters. 2012;32:395-406.

[20] Paull C, Dillon W. Natural gas hydrates: occurrence, distribution, and detection: American Geophysical Union, Washington, DC; 2001.

[21] Kvenvolden KA. Methane hydrate - A major reservoir of carbon in the shallow geosphere. Chemical Geology. 1988;71:41-51.

[22] Milkov AV. Global estimates of hydrate-bound gas in marine sediments: how much is really out there? Earth-Science Reviews. 2004;66:183-97.

[23] Wallmann K, Pinero E, Burwicz E, Haeckel M, Hensen C, Dale A, et al. The Global Inventory of Methane Hydrate in Marine Sediments: A Theoretical Approach. Energies. 2012;5:2449-98.

[24] Collett T, Johnson A, Knapp C, Boswell R. natural gas hydrates energy resource potential and associated geologic hazards. AAPG Memoir 89. 2010.

[25] Deusner C, Bigalke N, Kossel E, Haeckel M. Methane Production from Gas Hydrate Deposits through Injection of Supercritical CO2. Energies. 2012;5:2112-40.

[26] Moridis G, Collett T. Strategies for gas production from hydrate accumulations under various geologic conditions. 2003.

[27] Bishnoi PR, Natarajan V. Formation and decomposition of gas hydrates. Fluid Phase Equilibria. 1996;117:168-77. 
[28] Bishnoi PR, Natarajan V, Kalogerakis N. A Unified Description of the Kinetics of Hydrate Nucleation, Growth, and Decompositiona. Annals of the New York Academy of Sciences. 1994;715:311-22.

[29] Ohmura R, Ogawa M, Yasuoka K, Mori YH. Statistical Study of Clathrate-Hydrate Nucleation in a Water/Hydrochlorofluorocarbon System: Search for the Nature of the "Memory Effect". The Journal of Physical Chemistry B. 2003;107:5289-93.

[30] Ribeiro C, Lage P. Modelling of hydrate formation kinetics: State-of-the-art and future directions. Chemical Engineering Science. 2008;63:2007-34.

[31] Geddert T, Augustin W, Scholl S. Induction Time in Crystallization Fouling on Heat Transfer Surfaces. Chemical Engineering \& Technology. 2011;34:1303-10.

[32] Kashchiev D, Firoozabadi A. Induction time in crystallization of gas hydrates. Journal of Crystal Growth. 2003;250:499-515.

[33] McCallum SD, Riestenberg DE, Zatsepina OY, Phelps TJ. Effect of pressure vessel size on the formation of gas hydrates. Journal of Petroleum Science and Engineering. 2007;56:54-64.

[34] Sarshar M, Esmaeilzadeh F, Fathikaljahi J. Predicting the Induction Time of Hydrate Formation on a Water Droplet. Oil \& Gas Science and Technology-Revue De L Institut Francais Du Petrole. 2008;63:657-67.

[35] Skovborg P, Ng H, Rasmussen P, Mohn U. Measurement of induction times for the formation of methane and ethane gas hydrates. Chemical Engineering Science. 1993;48:445-53.

[36] Vysniauskas A, Bishnoi P. A kinetic study of methane hydrate formation. Chemical Engineering Science. 1983;38:1061-72.

[37] Wu Q, Zhang B. Memory effect on the pressure-temperature condition and induction time of gas hydrate nucleation. Journal of Natural Gas Chemistry. 2010;19:446-51.

[38] Anklam MR, Firoozabadi A. Driving force and composition for multicomponent gas hydrate nucleation from supersaturated aqueous solutions. Journal of Chemical Physics. 2004;121:11867-75.

[39] Arjmandi M, Tohidi B, Danesh A, Todd AC. Is subcooling the right driving force for testing low-dosage hydrate inhibitors? Chemical Engineering Science. 2005;60:1313-21.

[40] Beeskow-Strauch B, Schicks JM. The Driving Forces of Guest Substitution in Gas Hydrates-A Laser Raman Study on $\mathrm{CH}_{4}-\mathrm{CO}_{2}$ Exchange in the Presence of Impurities. Energies. 2012;5:420-37.

[41] Kashchiev D, Firoozabadi A. Driving force for crystallization of gas hydrates. Journal of Crystal Growth. 2002;241:220-30.

[42] Mottahedin M, Varaminian F, Mafakheri K. Modeling of methane and ethane hydrate formation kinetics based on non-equilibrium thermodynamics. Journal of Non-Equilibrium Thermodynamics. 2011;36:3-22.

[43] He Y, Rudolph ESJ, Zitha PLJ, Golombok M. Kinetics of $\mathrm{CO}_{2}$ and methane hydrate formation: An experimental analysis in the bulk phase. Fuel. 2011;90:272-9.

[44] Sabil KM, Duarte ARC, Zevenbergen J, Ahmad MM, Yusup S, Omar AA, et al. Kinetic of formation for single carbon dioxide and mixed carbon dioxide and tetrahydrofuran hydrates in water and sodium chloride aqueous solution. International Journal of Greenhouse Gas Control. 2010;4:798-805.

[45] Liu Y, Zhao J-F, Guo C-S, Song Y-C, Liu W-G, Cheng C-X, et al. Memory Effects of Structure I and II Gas Hydrates. Acta Physico-Chimica Sinica. 2011;27:1305-11.

[46] Takeya S, Hori A, Hondoh T, Uchida T. Freezing-Memory Effect of Water on Nucleation of $\mathrm{CO}_{2}$ Hydrate Crystals. The Journal of Physical Chemistry B. 2000;104:4164-8.

[47] Buchanan P, Soper AK, Thompson H, Westacott RE, Creek JL, Hobson G, et al. Search for memory effects in methane hydrate: Structure of water before hydrate formation and after hydrate decomposition. The Journal of Chemical Physics. 2005;123:164507.

[48] Rodger PM. Methane Hydrate: Melting and Memory. Annals of the New York Academy of Sciences. 2000;912:474-82. 
[49] Wilson PW, Haymet ADJ. Hydrate formation and re-formation in nucleating THF/water mixtures show no evidence to support a "memory" effect. Chemical Engineering Journal. 2010;161:146-50.

[50] Ruffine L, Donval JP, Charlou JL, Cremière A, Zehnder BH. Experimental study of gas hydrate formation and destabilisation using a novel high-pressure apparatus. Mar Petrol Geol. 2010;27:1157-65.

[51] Davies SR, Sloan ED, Sum AK, Koh CA. In Situ Studies of the Mass Transfer Mechanism across a Methane Hydrate Film Using High-Resolution Confocal Raman Spectroscopy. Journal of Physical Chemistry C. 2010;114:1173-80.

[52] Lee JD, Susilo R, Englezos P. Kinetics of structure H gas hydrate. Energy \& Fuels. 2005;19:1008-15.

[53] Moudrakovski IL, McLaurin GE, Ratcliffe CI, Ripmeester JA. Methane and carbon dioxide hydrate formation in water droplets: Spatially resolved measurements from magnetic resonance microimaging. Journal of Physical Chemistry B. 2004;108:17591-5.

[54] Youssef Z, Barreau A, Mougin P, Jose J, Mokbel I. Measurements of Hydrate Dissociation Temperature of Methane, Ethane, and CO2 in the Absence of Any Aqueous Phase and Prediction with the Cubic Plus Association Equation of State. Industrial \& Engineering Chemistry Research. 2009;48:4045-50.

[55] Youssef Z, Barreau A, Mougin P, Jose J, Mokbel I. Measurements of Hydrate Dissociation Temperature of Gas Mixtures in the Absence of Any Aqueous Phase and Prediction with the Cubic-Plus-Association Equation of State. Journal of Chemical and Engineering Data. 2010;55:2809-14. 
Table 1. Values of monitored parameters for methane hydrate formation at $274.6 \mathrm{~K}$ for and $10 \mathrm{MPa}$.

\begin{tabular}{|c|c|c|c|c|c|}
\hline Exp. & $\begin{array}{l}\text { Water } \\
\text { usages }\end{array}$ & $\begin{array}{l}\text { Waiting } \\
\text { time/h }\end{array}$ & $\begin{array}{l}\text { Induction } \\
\text { time/h }\end{array}$ & $p_{\text {formation }} / \mathrm{MPa}$ & $\Delta p_{72 h \text { later }} / \mathrm{MPa}$ \\
\hline \multirow{5}{*}{$A$} & 0 & - & 207 & 8.55 & 0.08 \\
\hline & 1 & 5 & 83.5 & 8.52 & 0.09 \\
\hline & 2 & 5 & 13.9 & 8.53 & 0.13 \\
\hline & 3 & 5 & 38.6 & 8.52 & 0.16 \\
\hline & 4 & 5 & 100.7 & 8.48 & - \\
\hline \multirow{5}{*}{ B } & 0 & - & 77 & 8.51 & 0.13 \\
\hline & 1 & 5 & 6.7 & 8.51 & 0.24 \\
\hline & 2 & 10 & 29.9 & 8.39 & 0.55 \\
\hline & 3 & 10 & 26.8 & 8.30 & 0.73 \\
\hline & 4 & 24 & 10 & 8.27 & - \\
\hline \multirow{5}{*}{ C } & 0 & - & 76.5 & 8.57 & 0.57 \\
\hline & 1 & 5 & 22.2 & 8.56 & 0.45 \\
\hline & 2 & 10 & 103.8 & 8.52 & 0.42 \\
\hline & 3 & 10 & 4.2 & 8.54 & 0.41 \\
\hline & 4 & 0.5 & 2.5 & 8.53 & - \\
\hline$D$ & 0 & - & 168.7 & 8.36 & - \\
\hline$E$ & 0 & - & 116.1 & 8.08 & - \\
\hline
\end{tabular}


Table 2. Values of monitored parameters for methane hydrate formation at $274.6 \mathrm{~K}$ for and $19.5 \mathrm{MPa}$.

\begin{tabular}{|c|c|c|c|c|c|}
\hline Exp. & $\begin{array}{l}\text { Water } \\
\text { usages }\end{array}$ & $\begin{array}{l}\text { Waiting } \\
\text { time/h }\end{array}$ & $\begin{array}{l}\text { Induction } \\
\text { time/h }\end{array}$ & $p_{\text {formation }} / \mathrm{MPa}$ & $\Delta p_{72 h \text { later }} / \mathrm{MPa}$ \\
\hline \multirow{5}{*}{$F$} & 0 & - & 0.5 & 16.73 & 0.88 \\
\hline & 1 & 5 & - & 16.11 & 0.27 \\
\hline & 2 & 10 & - & 16.02 & 0.24 \\
\hline & 3 & 10 & - & 15.80 & 0.19 \\
\hline & 4 & 24 & 0.4 & 16.38 & - \\
\hline \multirow[t]{3}{*}{$\mathrm{G}$} & 0 & - & 3.2 & 16.41 & 0.74 \\
\hline & 1 & 24 & 2.8 & 15.52 & 0.95 \\
\hline & 2 & 10 & 1.6 & 14.60 & - \\
\hline \multirow[t]{2}{*}{$\mathrm{H}$} & 0 & - & 18.2 & 16.71 & 0.44 \\
\hline & 1 & 1 & 0.3 & 17.20 & 0.13 \\
\hline \multirow[t]{2}{*}{1} & 0 & - & 18 & 16.37 & 0.28 \\
\hline & 1 & 24 & - & 16.03 & 0.22 \\
\hline $\mathrm{J}$ & 0 & - & 3.9 & 16.73 & 0.31 \\
\hline
\end{tabular}




\section{Figures}

Figure 1. Schematic diagram of the apparatus. Elements: $(T)$ temperature probe, $(P)$ pressure transducer, (TR) thermal regulator, (VP) vacuum pump.

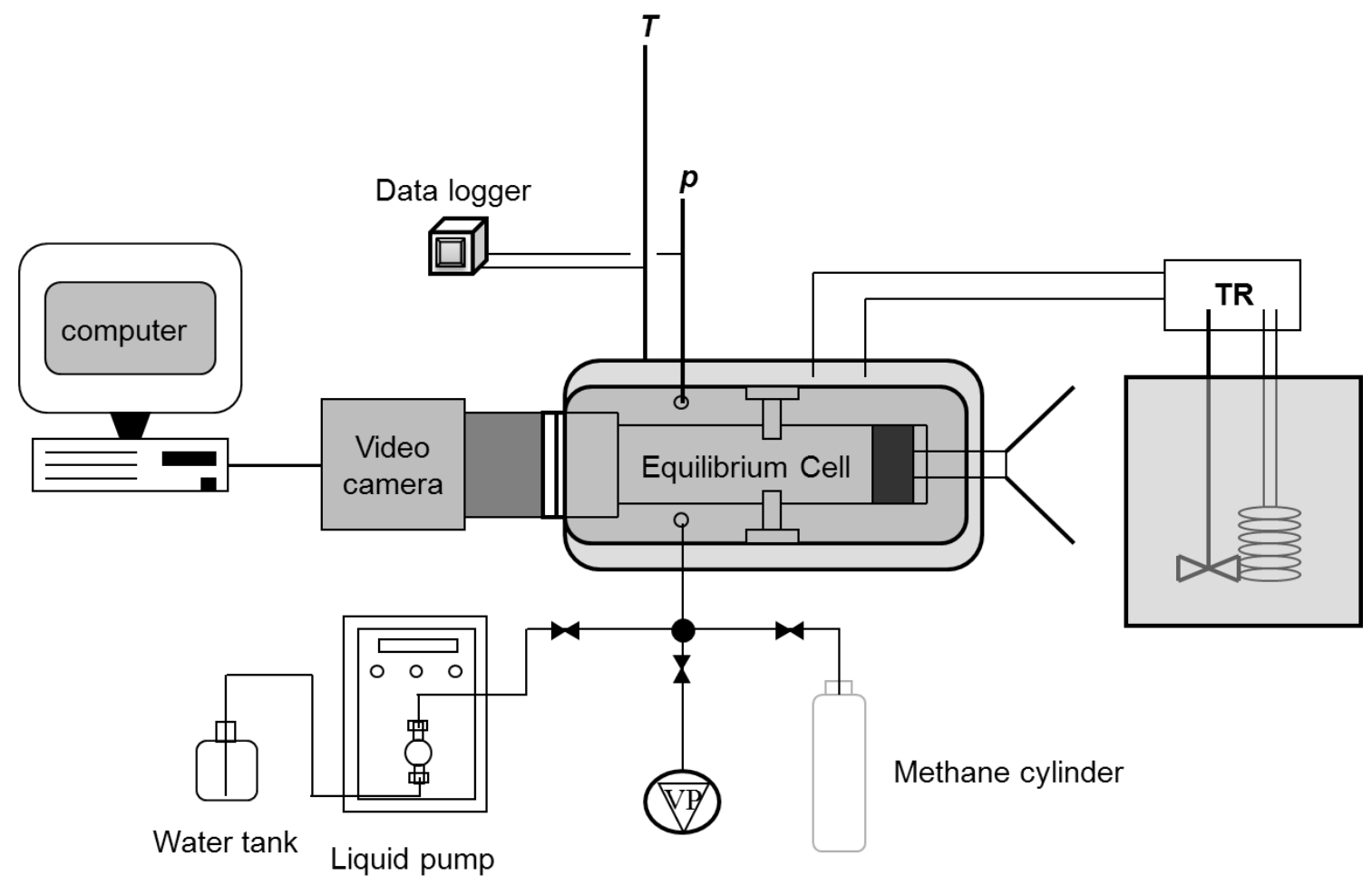

Figure 2. Example of temperature profile from Experiment $A$.

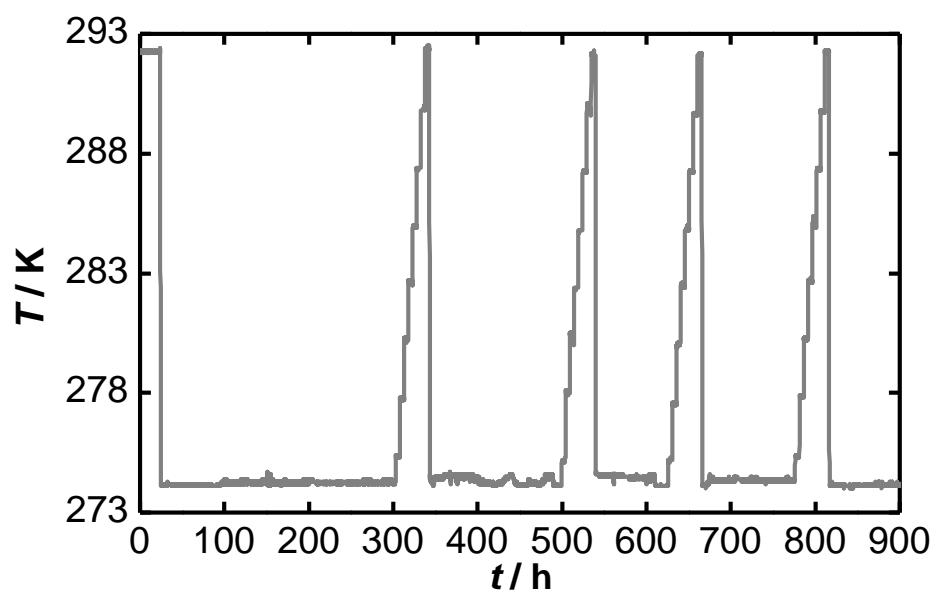


Figure 3. Example of temperature- pressure trace for methane hydrates formation using the isochoric procedure at two pressure ranges. Data of $(+)$ cooling, $(\square)$ formation and $(\bullet)$ dissociation step. Dotted line shows the limit of the stability region for this system.
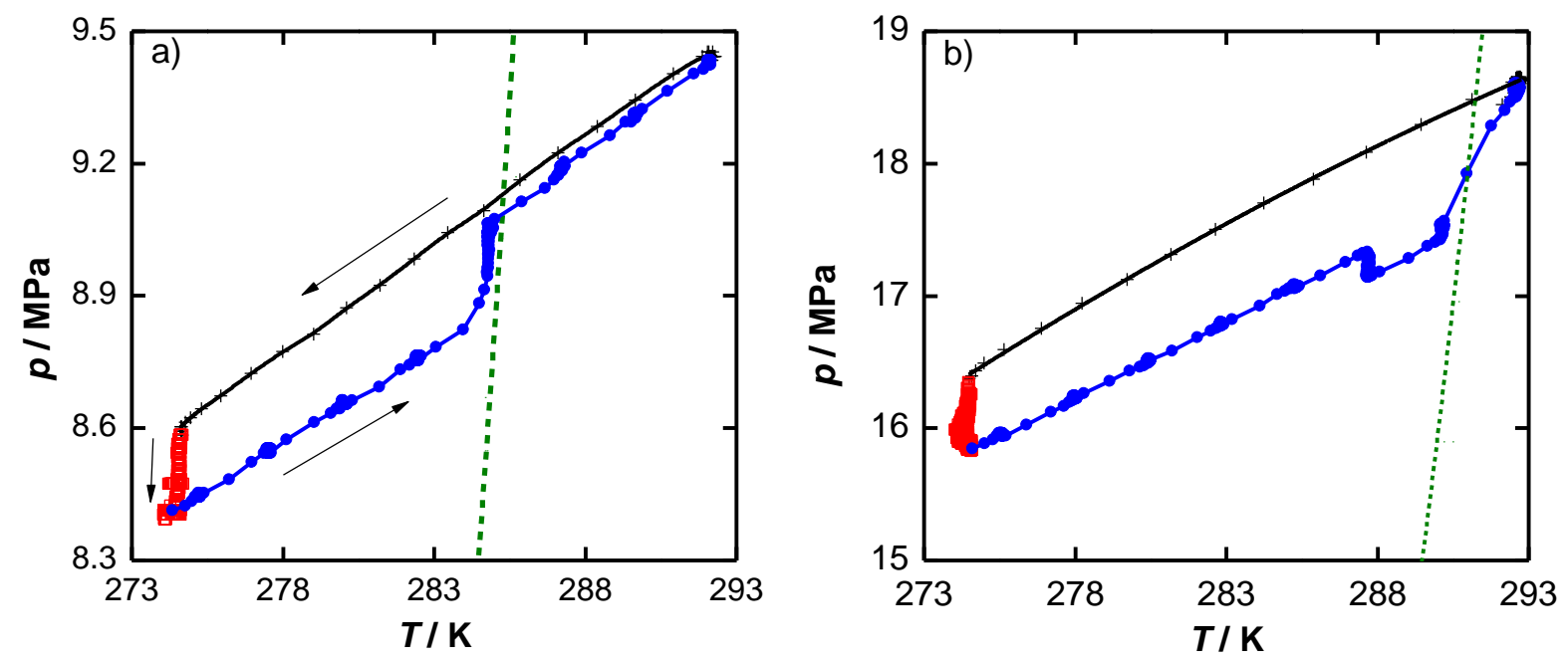

Figure 4. Methane hydrate growth using fresh water under quiescent conditions for Experiment A: a) before cooling, b) after cooling, c) $34 \mathrm{~h}$, d) $58 \mathrm{~h}$ and e) $66 \mathrm{~h}$ after hydrate formation.

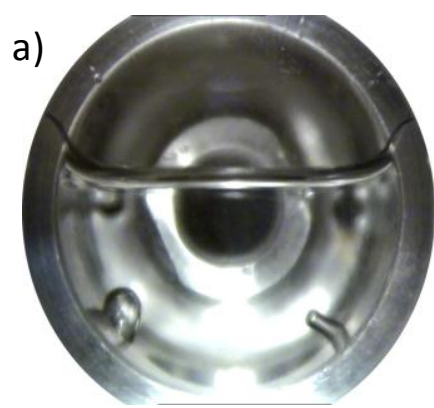

(292.3 K , 9.6 MPa)

d)

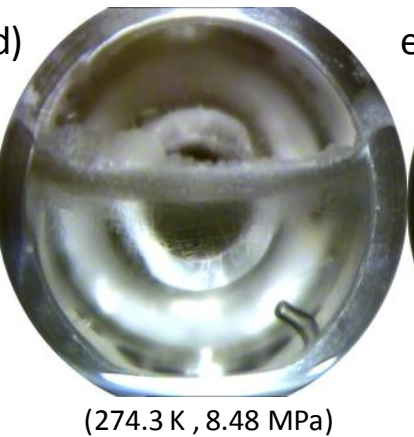

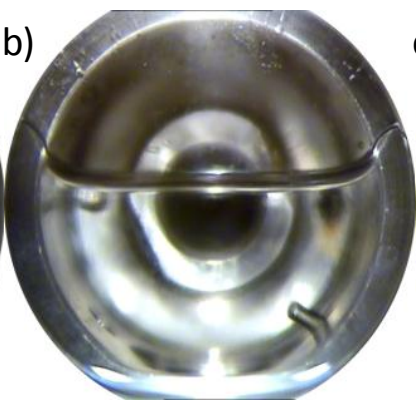

(274.2 K , 8.56 MPa)

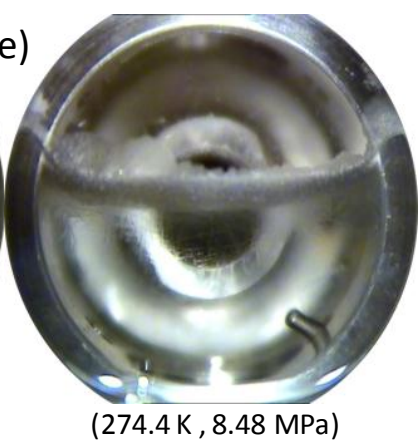

c)

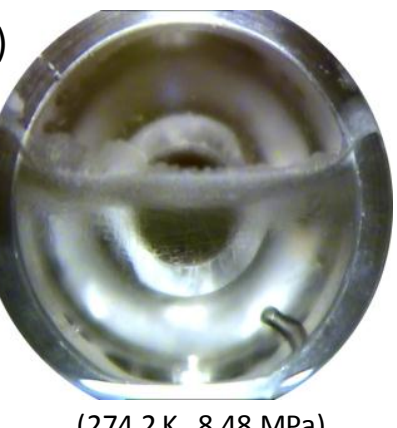

(274.2 K , 8.48 MPa) 
Figure 5. Methane hydrate growth using fresh water under quiescent conditions for Experiment F: a) before cooling, b) $28 \mathrm{~min}$, c) $30 \mathrm{~min}, \mathrm{~d}) 5 \mathrm{~h}$, e) $23 \mathrm{~h}$ and f) $72 \mathrm{~h}$ after hydrate formation.

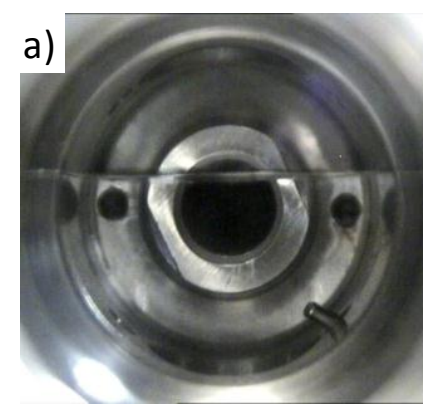

(292.5 K, 19.2 MPa)

d)

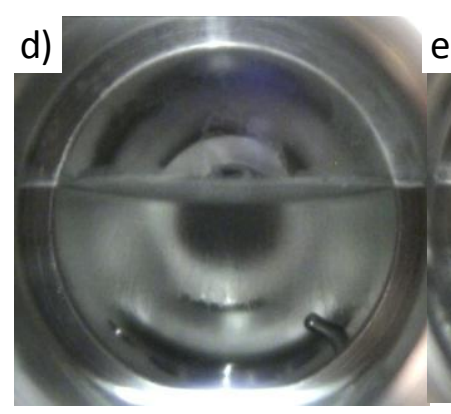

(274.5 K, 16.3 MPa)

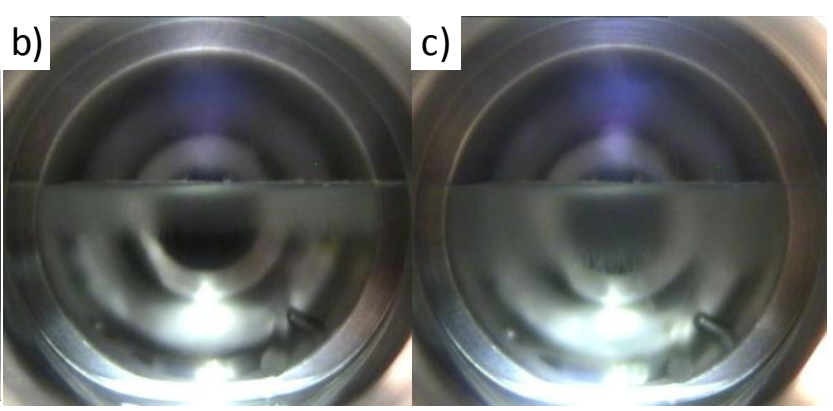

$(273.7 \mathrm{~K}, 16.6 \mathrm{MPa})$

$(273.3 \mathrm{~K}, 16.6 \mathrm{MPa})$

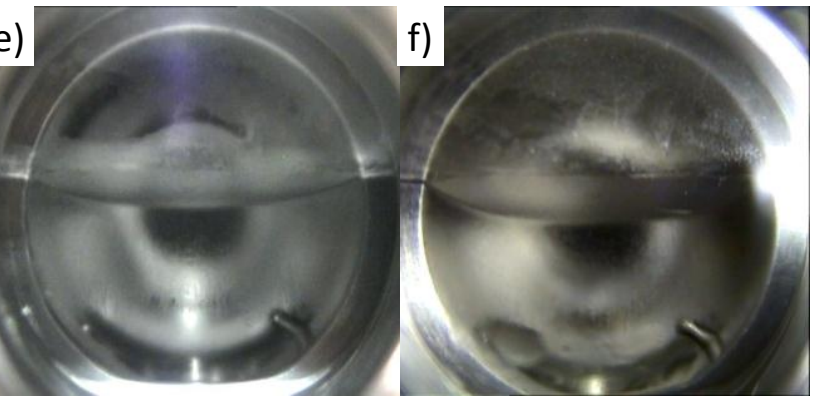

$(274.5 \mathrm{~K}, 16.1 \mathrm{MPa})$

(274.5 K , 15.9 MPa) 
Figure 6. Methane-hydrate distribution within the cell chamber after $72 \mathrm{~h}$ of growth for successive hydrate formation/ dissociation cycles from Experiment B.

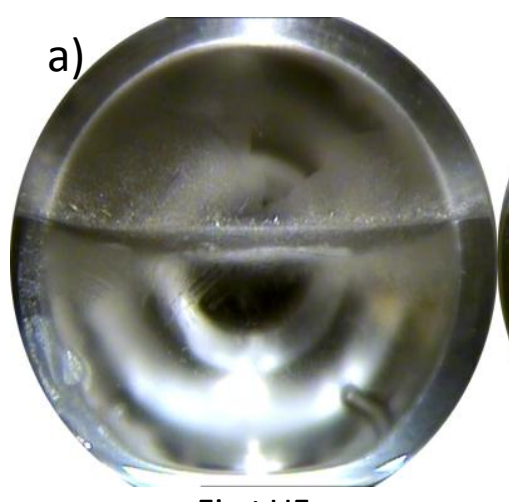

First HF

(274.4 K, 8.4 MPa)

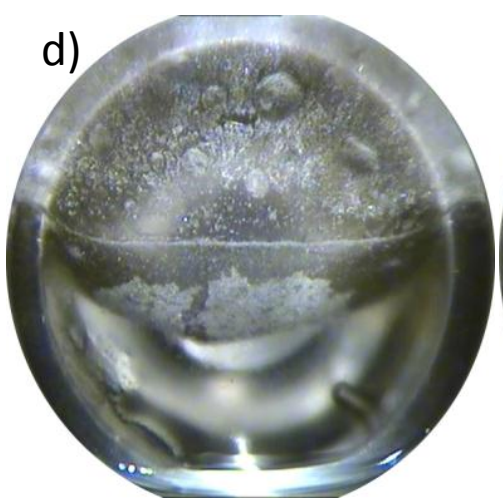

Fourth HF

(274.2 K, 7.6 MPa)

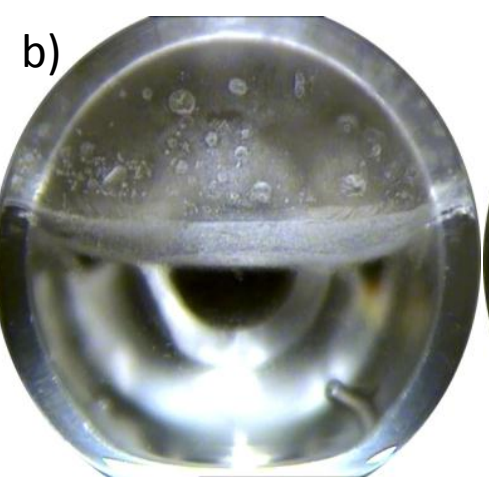

Second HF

(274.6 K, 8.3 MPa)

e)

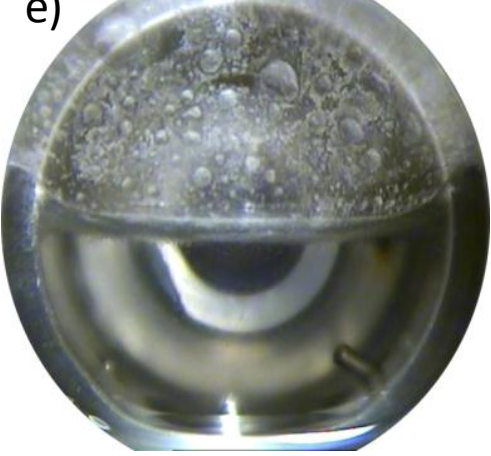

Fifth HF

(274.3 K, 8.1 MPa)

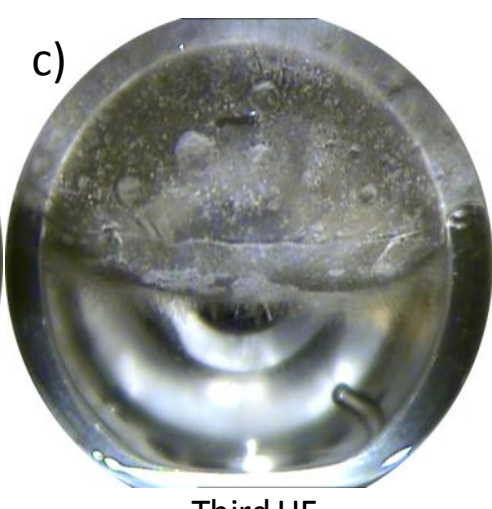

Third HF

(274.6 K, 7.9 MPa) 
Figure 7. Evolution of the pressure and temperature during methane-hydrate formation for the first cycle at $10 \mathrm{MPa}$. (- -) Temperature profile and pressure profiles for experiences: $(\circ)$ $\mathrm{A},(+) \mathrm{B},(\nabla) \mathrm{C},(\square) \mathrm{D}$ and $(\triangle) \mathrm{E}$.

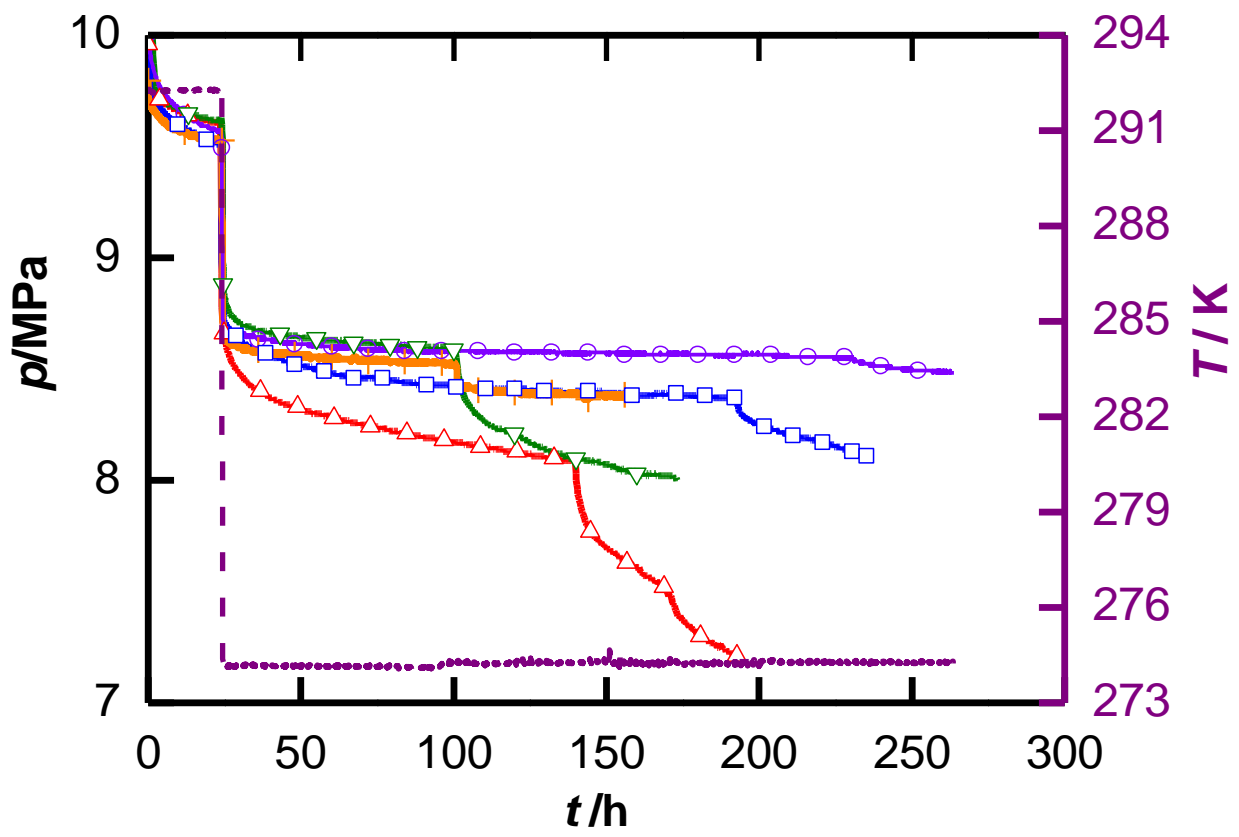

Figure 8. Evolution of the pressure and temperature with time during methane-hydrate formation for the first cycle at $19.5 \mathrm{MPa}$. (- -) Temperature profile and pressure profiles for experiences: $(\diamond) \mathrm{F},(+) \mathrm{G},(\boldsymbol{\Delta}) \mathrm{H},(\bullet) \mathrm{I}$ and $(\square) \mathrm{J}$. Arrows on the magnified view represent the incipient hydrate formation.

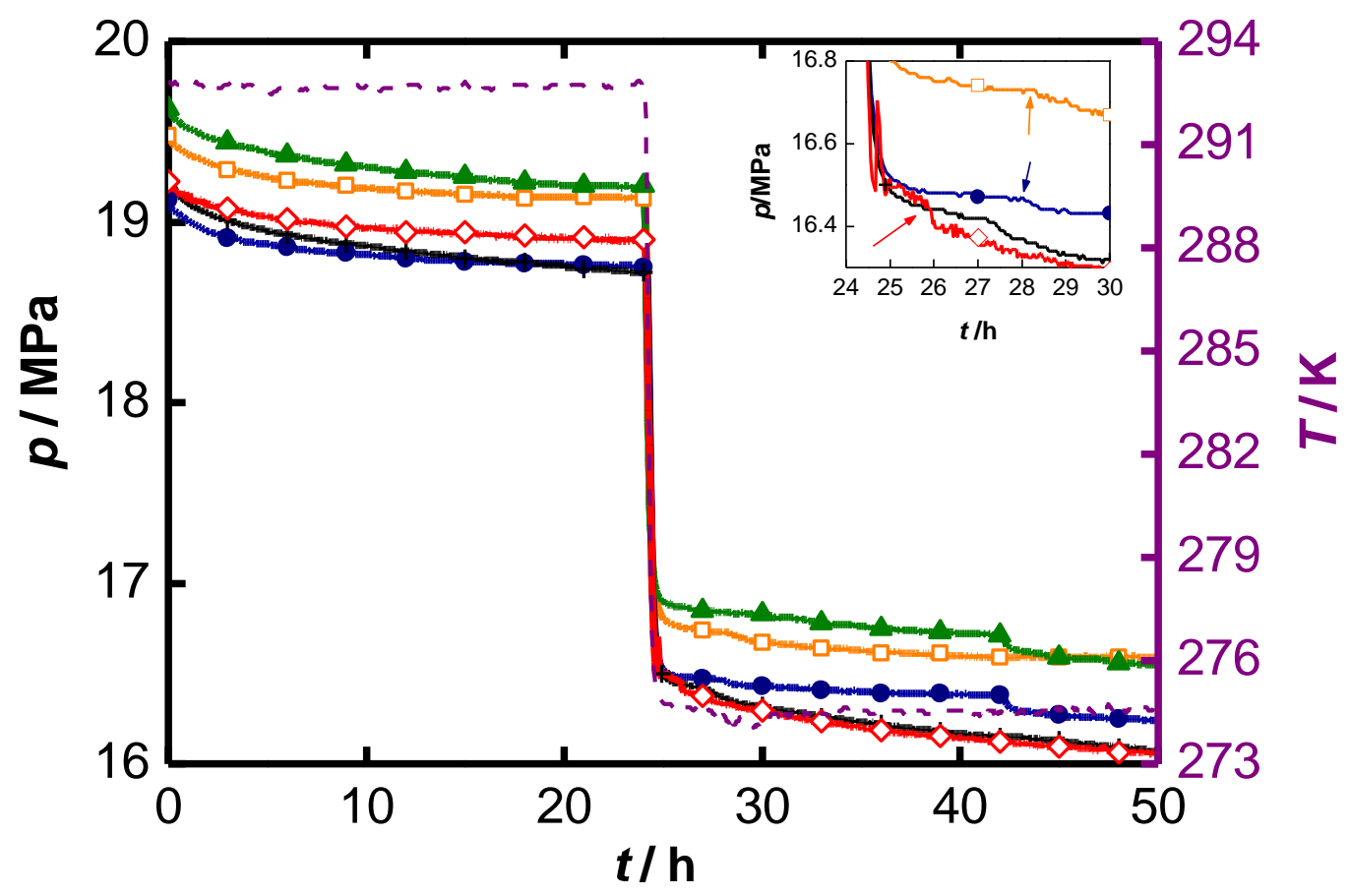


Figure 9. Evolution of the pressure and temperature with time over five consecutive formation/dissociation cycles. (- -) Temperature and (-) pressure profiles for a) Experiment $A, b)$ Experiment $B, c)$ Experiment $C$ and d) Experiment $F$.
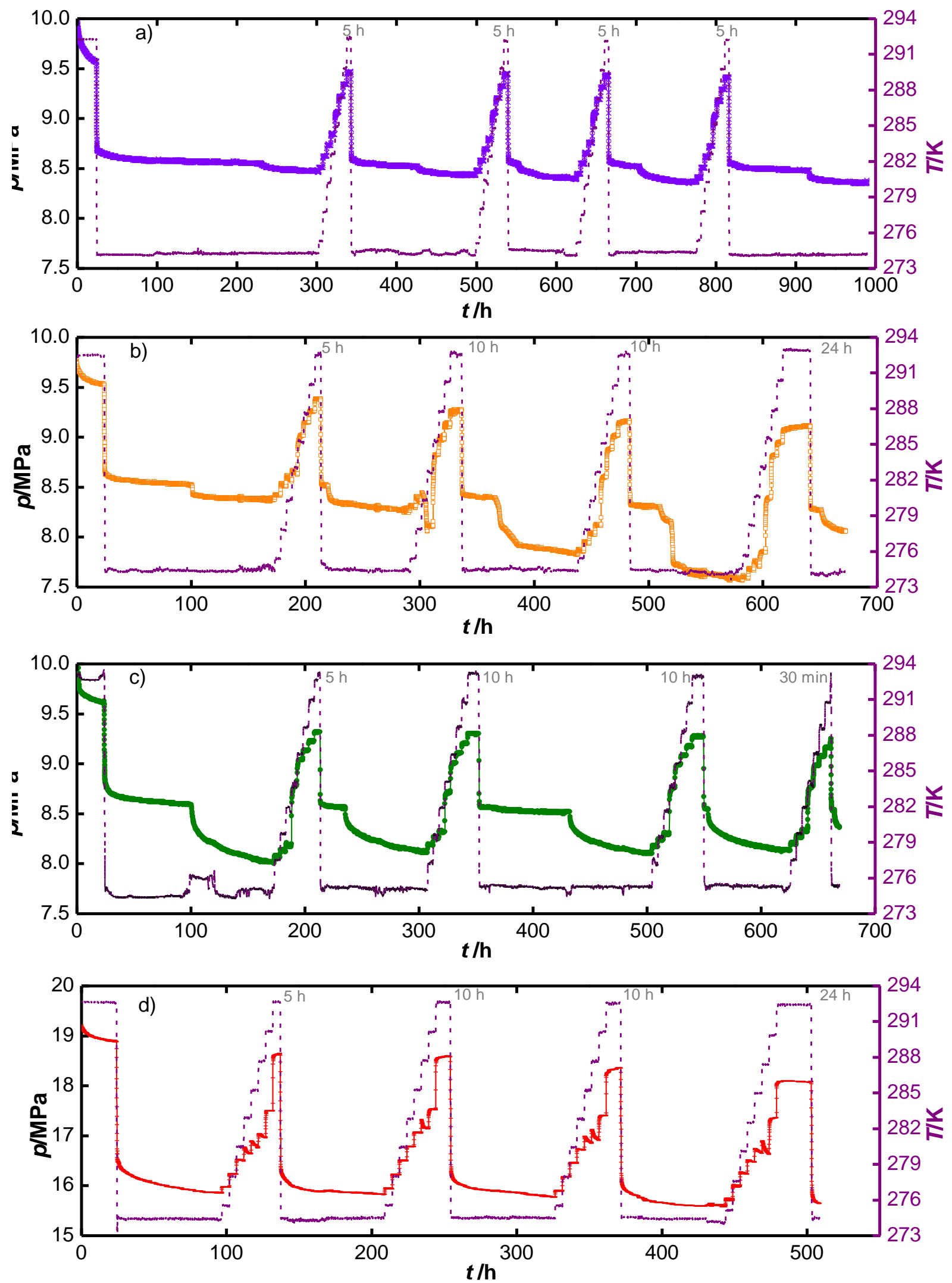